\title{
Toward high recovery and selective leaching of zinc from electric arc furnace dust with different physicochemical properties
}

\author{
Han Saem Lee ${ }^{1}$, Da So Mi Park ${ }^{2}$, Yuhoon Hwang ${ }^{2}$, Jong Gil Ha ${ }^{3}$, Hyung Sang Shin ${ }^{+}$ \\ ${ }^{1}$ Department of Environmental Energy Engineering, Seoul National University of Science and Technology, Seoul 01811, Republic of Korea \\ ${ }^{2}$ Department of Environmental Engineering, Seoul National University of Science and Technology, Seoul 01811, Republic of Korea \\ ${ }^{3}$ Jeongsoo New Technology, LTD., Seoul 02792, Republic of Korea
}

\begin{abstract}
This work describes highly efficient recovery and selective leaching of $\mathrm{Zn}$ from electric arc furnace dust (EAFD) with different physicochemical properties, induced by acid leaching at ambient conditions. The chemical compositions, mineralogical phases, and particle sizes of the EAFDs were analyzed and compared. The effects of leaching time, liquid/solid ratio, acid type, and acid concentration on the selective leaching of $\mathrm{Zn}$ were also studied. The EAFD with high $\mathrm{Fe} / \mathrm{Zn}$ ratio $\left(>1, \mathrm{EAFD}_{3}\right)$ was richer in $\mathrm{ZnFe}_{2} \mathrm{O}_{4}$ and exhibited larger particle size than samples with low $\mathrm{Fe} / \mathrm{Zn}$ ratio $\left(<1, \mathrm{EAFD}_{1,2}\right)$. ANOVA analysis revealed that the $\mathrm{Fe} / \mathrm{Zn}$ ratios of the EAFDs also have a significant effect on $\mathrm{Zn}$ extraction $(p<0.005)$. Selective leaching of $\mathrm{Zn}$ with minimum Fe dissolution was obtained at $\mathrm{pH}>4.5$, regardless of other parameters or sample properties. The maximum $\mathrm{Zn}$ extraction rate obtained by the $\mathrm{pH}$ control was over $97 \%$ for EAFD 1 and $\mathrm{EAFD}_{2}, 76 \%$ for $\mathrm{EAFD}_{3}$, and $80 \%$ for $\mathrm{EAFD}$. The present results confirm that the $\mathrm{Fe} / \mathrm{Zn}$ ratio can be used to identify EAFDs that permits facile and high-yield $\mathrm{Zn}$ recovery, and pH can be used as a process control factor for selective leaching of $\mathrm{Zn}$ regardless of any differences in the properties of the EAFD sample.
\end{abstract}

Keywords: Acid leaching, Electric arc furnace dust, pH, Physicochemical characteristics, Zinc leaching

\section{Introduction}

Electric arc furnace dust (EAFD) is the solid waste recovered from dust collectors [1]. Approximately 10-30 kg of EAFD is produced per ton of steel [2]. EAFD is considered a hazardous waste because unsafe metals (e.g., lead and cadmium) [3] may have been incorporated during the steelmaking process or used as alloying elements and plated onto steel scraps [4]. EAFD usually contains $10-50$ wt\% of Zn, which can be used as high-value products [4]. Hence, EAFD has been actively recycled to recover Zn. Zn extraction from EAFD may also allow reuse of residues as raw materials for steelmaking and reduce the quantity of EAFD left for disposal $[5,6]$.

The pyrometallurgical method, which is a dry process, is only suitable for high-volume EAFD recycling owing to high initial investment and operational costs [5]. The hydrometallurgical method using alkali or acid has attracted significant attention over the last decade. In particular, the acid-based wet process affords a high Zn recovery rate by using high temperatures, pressures, or acid concentrations, and has lower operating costs than the alkali wet process [1-4]. High Zn recoveries of 92\% [7] and > $97 \%$ [8] have been achieved using various acid leaching processes. However, as the recovery of $\mathrm{Zn}$ is highly dependent on the EAFD characteristics, such as the ferrite content and particle size, ensuring consistent recovery yields is challenging. As each EAFD has different properties, specifying appropriate process conditions for $\mathrm{Zn}$ recovery by acid leaching is difficult $[5,9]$. Only a few studies have analyzed the different features of various types of EAFDs and the effect of their distinctive characteristics on $\mathrm{Zn}$ recovery [10]. Consequently, an acid leaching process has not been widely commercialized and there are no available methods for selecting EAFDs showed consistently high Zn recovery yields. Thus, there is a need to develop a method that enables the selection of suitable EAFDs for the recycling processes by considering the characteristics of the samples. Although higher $\mathrm{Zn}$ ferrite $\left(\mathrm{ZnFe}_{2} \mathrm{O}_{4}\right.$, franklinite) contents in the EAFD are known to make $\mathrm{Zn}$ recovery more difficult $[8,9]$, there is no known method for easily estimating the amount of $\mathrm{ZnFe}_{2} \mathrm{O}_{4}$ in the EAFD during recovery by acid leaching [11].
This is an Open Access article distributed under the terms of the Creative Commons Attribution Non-Commercial License (http://creativecommons.org/licenses/by-nc/3.0/) which permits unrestricted non-commercial use, distribution, and reproduction in any medium, provided the original work is properly cited.

Copyright (C) 2020 Korean Society of Environmental Engineers
Received April 2, 2019 Accepted May 15, 2019

${ }^{\dagger}$ Corresponding author

Email: hyuns@seoultech.ac.kr

Tel: +82-2-970-6645 Fax: +82-2-971-5776

ORCID: 0000-0002-5197-8645 
Therefore, it is important to determine specific properties that make an EAFD suitable for efficient acid leaching and need a selecting factor with detailed criterion for choosing an appropriate EAFD in the acid leaching process.

Another disadvantage of the acid leaching process is the simultaneous leaching of $\mathrm{Fe}$ with $\mathrm{Zn}$ [5]. Among the various forms of $\mathrm{Zn}$ in EAFDs [3, 6], $\mathrm{ZnFe}_{2} \mathrm{O}_{4}$ is highly resistant to dissolution under normal acid leaching conditions. Therefore, $\mathrm{Zn}$ recovery from $\mathrm{ZnFe}_{2} \mathrm{O}_{4}$ has required harsher conditions, including high temperatures, high pressures, and high acid concentrations during leaching [12]. However, these methods suffer from large amounts of Fe leaching and high energy costs. It is therefore highly desirable to develop an acid leaching technique with improved $\mathrm{Zn}$ recovery without Fe and low energy consumption [6]. Crystallization, ion exchange, solvent extraction, and oxidation followed by precipitation are all effective for controlling Fe leaching or removing leached Fe via a wet-acid process [13, 14]. Although these previous methods increased the removal efficiency of Fe, they still required high temperatures and pressures, consumed significant energy, and required an additional step to separate $\mathrm{Zn}$ and Fe. The precipitation method using $\mathrm{pH}$ for removing $\mathrm{Fe}$ from leaching solution has been reported to have good separation efficiency and no additional step in previous studies [8, 9]. Unfortunately, despite this simple method for removing Fe, it has not been widely evaluated whether Fe can be consistently removed via $\mathrm{pH}$ control under various EAFD and acid leaching conditions.

Herein, we investigated the characteristics of EAFD that could affect Zn leaching and the acid leaching conditions that could allow the effective recovery of $\mathrm{Zn}$ while minimizing Fe leaching from EAFD at room temperature and atmospheric pressure. The effects of the physicochemical properties (elemental composition, crystallinity, grain size, and morphology) of four different EAFDs on acid leaching were compared. The effects of operating factors such as acid type $\left(\mathrm{H}_{2} \mathrm{SO}_{4}, \mathrm{HCl}\right)$, acid concentration, L/S ratio, and leaching time on the leaching behavior of $\mathrm{Zn}$ and Fe were also investigated as a function of $\mathrm{pH}$. The main objective of this study was to identify specific properties of EAFD that will give consistent and high Zn recovery rates, allowing efficient operation of acid leaching process, and to confirm that $\mathrm{pH}$ can be used as a process control parameter to attain consistent leaching of $\mathrm{Zn}$ without $\mathrm{Fe}$ from various EAFDs in an acid leaching process.

\section{Materials and Methods}

Four EAFD samples $\left(\mathrm{EAFD}_{1}, \mathrm{EAFD}_{2}, \mathrm{EAFD}_{3}\right.$, and $\left.\mathrm{EAFD}_{4}\right)$ were obtained from 'H' steel mill (Dangjin, Chungnam Province, South Korea) and used as received. The EAFDs were collected at appropriate time intervals from the same electric steelmaking furnace and fully dried in air before use. For comparison, $\mathrm{Zn}$ oxide ( $\mathrm{ZnO}$, Sigma-Aldrich Co.), $\mathrm{ZnFe}_{2} \mathrm{O}_{4}$ (50 nm, Aladdin Industrial Co.), and Fe oxide $\left(\mathrm{Fe}_{2} \mathrm{O}_{3}, \mathrm{Fe}_{3} \mathrm{O}_{4}\right.$, Sigma-Aldrich Co. $)$ reagents were used.

For elemental analyses, the EAFDs ( $0.1 \mathrm{~g}$ ) were dissolved by ultrasonic acid dissolution (MARS 6, CEM Co.) using $100 \mathrm{~mL}$ of an acid solution prepared by adding $5 \mathrm{~mL}$ each of $\mathrm{HNO}_{3}, \mathrm{HCl}$, $\mathrm{HF}$, and aqua regia, followed by digestion under microwave irradiation at $210^{\circ} \mathrm{C}$ for $60 \mathrm{~min}[4,15]$. Elemental compositions were determined by inductively coupled plasma mass spectrometry (ICP-MS; iCAP-Q, Thermo Fisher Scientific). The mineralogical phase of each EAFD was analyzed by X-ray diffraction (XRD; $\mathrm{Cu}-\mathrm{K}$, DE/D8 Advance, Bruker Co.) at $40 \mathrm{kV}$ and $40 \mathrm{~mA}$, and the XRD peaks were assigned using the EVA library (Version 3.0, Bruker Co.). Particle size analysis was performed using a laser scattering particle size analyzer (Mastersizer 3000, Malvern Co.). Scanning electron microscopy with energy-dispersive spectrometry (SEM-EDS; SU8010, Hitachi Co.) was used to identify the mineralogical species and morphologies of the EAFDs and acid leaching residues.

Two-way analysis of variance (ANOVA) was used to evaluate the interactive effects of the Fe-to-Zn ratio (Fe/Zn, w/w) and the specific particle size $\left(\mathrm{d}_{50}\right)$ on $\mathrm{Zn}$ extraction from the EAFDs and to characterize the EAFDs that offer a high rate of Zn recovery at room temperature under normal pressure, irrespective of the other conditions. ANOVA was implemented on 17 data points, including published results (Table 1), using the SPSS statistics program (Version 18.0). Here, the Zn extraction levels (\%) refer to the maximum extractable $\mathrm{Zn}$ content (from both $\mathrm{ZnO}$ and $\mathrm{ZnFe}_{2} \mathrm{O}_{4}$ ) in the EAFD by $\mathrm{H}_{2} \mathrm{SO}_{4}$ leaching under the optimized conditions (L/S ratio, acid concentration, and leaching time) at room temperature and under normal pressure. The variances and their levels, which were assigned by referring to the empirical data, are assigned to $\mathrm{Fe} / \mathrm{Zn}$ ratio of 3 levels $(\leq 1 ; 1<\mathrm{Fe} / \mathrm{Zn}$ ratio $\leq 3 ; 3<)$ and particle size of 2 levels $(\leq 5 ; 5<)$.

Acid leaching experiments were performed as batch experiments in a $0.5 \mathrm{~L}$ Pyrex reactor vessel with an L/S ratio of 3 and a stirring rate of $300 \mathrm{rpm}$, which were set based on our preliminary results and related literature results on the acid leaching of EAFD [6] under constant temperature and pressure $\left(20^{\circ} \mathrm{C}, 1.0 \mathrm{~atm}\right)$. Leaching experiments with varying leaching times (0-120 $\mathrm{min}), \mathrm{L} / \mathrm{S}$ ratios (1-10 $\mathrm{mL} / \mathrm{g})$, acid types $\left(\mathrm{H}_{2} \mathrm{SO}_{4}, \mathrm{HCl}\right)$, and acid concentrations (0-3 $\mathrm{mol} / \mathrm{L} \mathrm{H}_{2} \mathrm{SO}_{4}, 0-4 \mathrm{~mol} / \mathrm{L} \mathrm{HCl}$ ) were conducted in $100 \mathrm{~mL}$ of acid solution. Small aliquots $(5 \mathrm{~mL})$ taken at regular time intervals were immediately filtered using a cellulose acetate filter $(0.2 \mu \mathrm{m}$, Adventec) to remove residual particles. $\mathrm{Zn}$ and $\mathrm{Fe}$ in the leachates were diluted with $1 \%$ aqueous $\mathrm{HNO}_{3}$ and analyzed by atomic absorption spectrometry (AAS; Solaar M6, Thermo Scientific). The $\mathrm{pH}$ of the leachate was measured using a $\mathrm{pH}$ meter (Orion Star A211, Thermo Scientific) after filtration. Residual EAFDs after leaching were washed with water 2-3 times and collected by centrifugation $(10,000 \mathrm{rpm}$, Hanil SUPRA $25 \mathrm{~K})$. After drying at $105^{\circ} \mathrm{C}$, the residues were analyzed using XRD and SEM-EDS.

\section{Results and Discussion}

\subsection{Physicochemical Properties of EAFDs}

To establish the differences between the four EAFDs used in this study, the elemental compositions, particle size distributions, and Zn extraction levels were examined (Table 1). Literature values are also included for comparison. Both the $\mathrm{Zn}$ and Fe contents in $\mathrm{EAFD}_{1-4}$ were $10-30 \%$, while the calcium and lead contents were $2-10 \%$ and $0.2-2 \%$, respectively. The Fe/Zn ratios in $\mathrm{EAFD}_{1}$ and $\mathrm{EAFD}_{2}$ were 0.81 and 0.72 , respectively. $\mathrm{EAFD}_{3}$ and $\mathrm{EAFD}_{4}$ 


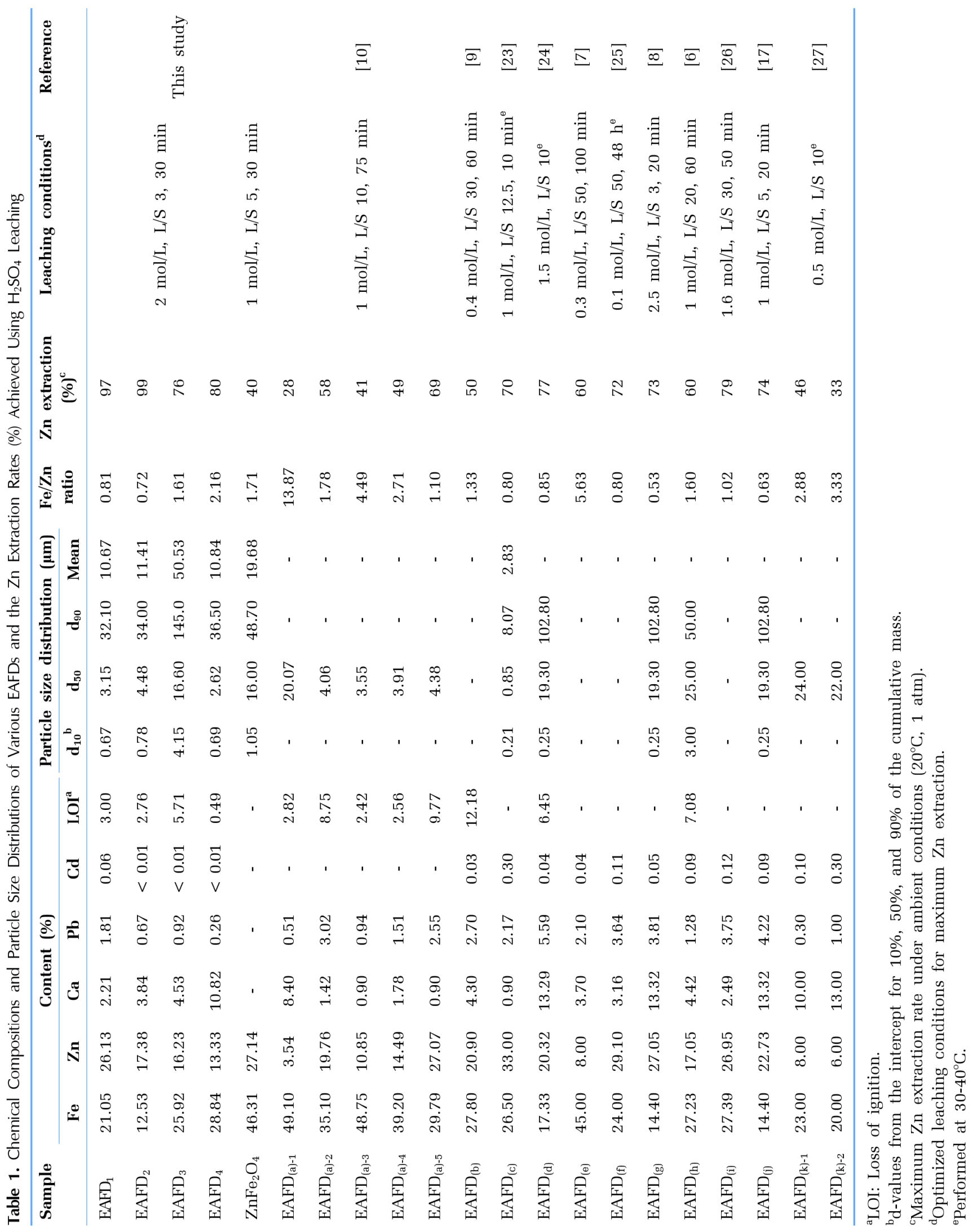


exhibited markedly higher $\mathrm{Fe} / \mathrm{Zn}$ ratios of 1.61 and 2.16, respectively. A high $\mathrm{Fe} / \mathrm{Zn}$ ratio increases the possibility that $\mathrm{Zn}$ will react with $\mathrm{Fe}$ oxide during high-temperature smelting to form $\mathrm{ZnFe}_{2} \mathrm{O}_{4}[5,10]$. To confirm this, the XRD patterns of $\mathrm{EAFD}_{1-4}$ were compared (Fig. 1). In $\mathrm{EAFD}_{1,2}$, the $\mathrm{ZnFe}_{2} \mathrm{O}_{4}$ and $\mathrm{ZnO}$ peak intensities were similar. By contrast, $\mathrm{EAFD}_{3,4}$, with relatively high Fe content, exhibited a higher peak intensity for $\mathrm{ZnFe}_{2} \mathrm{O}_{4}$ than for $\mathrm{ZnO}$. In previous studies, EAFDs with a high $\mathrm{Fe} / \mathrm{Zn}$ ratio $\left(\mathrm{EAFD}_{(\mathrm{h})}\right.$, Table 1) exhibited a high-intensity $\mathrm{ZnFe}_{2} \mathrm{O}_{4}$ peak similar to that observed for $\mathrm{EAFD}_{3,4}$, whereas EAFDs with a low Fe/Zn ratio $\left(\mathrm{EAFD}_{(\mathrm{d}, \mathrm{e}, \mathrm{f})}\right.$, Table 1) displayed XRD patterns similar to those of $\mathrm{EAFD}_{1,2}$. Thus, higher $\mathrm{Fe} / \mathrm{Zn}$ ratios correspond to a higher fraction of $\mathrm{Zn}$ existing in its mineralogical form, i.e., $\mathrm{ZnFe}_{2} \mathrm{O}_{4}$, in the EAFD. Similarly, Machado et al. [15] determined using Mössbauer spectroscopy that EAFDs with $\mathrm{Fe} / \mathrm{Zn}$ ratios of 5.3 contain 15 times more $\mathrm{ZnFe}_{2} \mathrm{O}_{4}$ than $\mathrm{ZnO}$.

The mean particle size of $\mathrm{EAFD}_{1}$ and its $\mathrm{d}_{50}$ value (the median diameter) were $10.67 \mu \mathrm{m}$ and $3.15 \mu \mathrm{m}$, respectively (Fig. 2). The mean particle size of $\mathrm{EAFD}_{2}(11.41 \mu \mathrm{m})$ was similar to that of $\mathrm{EAFD}_{1}$. By contrast, $\mathrm{EAFD}_{3}$ displayed a larger particle size distribution $\left(\mathrm{d}_{50}=16.60 \mu \mathrm{m}\right)$, with a mean particle size of 50.53 $\mu \mathrm{m}$. The mean particle size of $\mathrm{ZnFe}_{2} \mathrm{O}_{4}$ and its $\mathrm{d}_{50}$ values were $19.68 \mu \mathrm{m}$ and $16.00 \mu \mathrm{m}$, respectively, very similar to the values for $\mathrm{EAFD}_{3}$. These results agree well with the results of the elemental and mineralogical phase analysis, indicating that an EAFD with a high $\mathrm{ZnFe}_{2} \mathrm{O}_{4}$ content may have a relatively large particle size distribution [2, 16]. Similarly, Montenegro et al. [8] used SEM analysis to show that $\mathrm{ZnO}$ in EAFD is mainly present as fine particles, while spinel-type $\mathrm{ZnFe}_{2} \mathrm{O}_{4}$ adopts larger spherical particles. Further, Suetens et al. [12] noted that EAFD particles of $<1 \mu \mathrm{m}$ are composed mostly of $\mathrm{ZnO}$.

SEM-EDS analyses of $\mathrm{EAFD}_{1}$ and $\mathrm{EAFD}_{3}$ revealed that the mineralogical phases and morphologies (Fig. 3) differed depending on the Fe/Zn ratio. The EAFD particles were mostly spherical with various sizes, and notably, $\mathrm{EAFD}_{1}(\mathrm{Fe} / \mathrm{Zn}$ ratio $<1)$ had more spherical-shaped particles covered by fine particles



Fig. 1. XRD patterns of $\mathrm{EAFD}_{1-4}$ and their residues (denoted by ' $\mathrm{R}^{\prime}$ ) after acid leaching $\left(0.5 \mathrm{~mol} / \mathrm{L} \mathrm{H}_{2} \mathrm{SO}_{4}, \mathrm{~L} / \mathrm{S}\right.$ ratio $=3$, reaction time $=30 \mathrm{~min}, 20^{\circ} \mathrm{C}$ ).

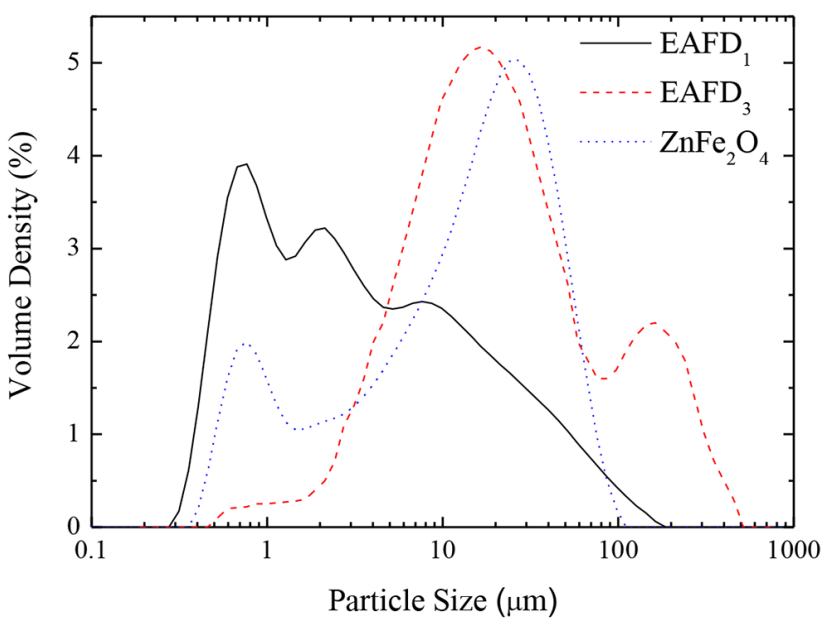

Fig. 2. Particle size distributions of EAFD samples and zinc ferrite reagent.

than $\mathrm{EAFD}_{3}\left(\mathrm{Fe} / \mathrm{Zn}\right.$ ratio $>$ 1). In $\mathrm{EAFD}_{1}$ (Fig. 3(a)), $\mathrm{ZnFe}_{2} \mathrm{O}_{4}$ existed as relatively large spherical crystals covered in small spherical crystals of $\mathrm{ZnO}$. Interestingly, $\mathrm{ZnO}$ in $\mathrm{EAFD}_{3}$ instead appeared as needle-shaped particles. These results were confirmed by SEM-EDS mapping (Fig. 4). The SEM image of $\mathrm{ZnO}$ reveals that various crystal shapes were generated depending on the $\mathrm{ZnO}$ generation conditions. Meanwhile, the $\mathrm{ZnFe}_{2} \mathrm{O}_{4}$ crystals in $\mathrm{EAFD}_{3}$ were large and spherical with relatively smooth surfaces not covered in fine particles. These results agree well with the morphologies of EAFD particles reported previously [15, 17].

\subsection{The Relationship between $\mathrm{Fe} / \mathrm{Zn}$ Ratio, $d_{50}$, and $\mathrm{Zn}$ Extraction Rate}

To investigate the main characteristics of EAFDs that affect $\mathrm{Zn}$ extraction, ANOVA was performed using the $\mathrm{Fe} / \mathrm{Zn}$ ratio and $\mathrm{d}_{50}$, which are considered closely related to the $\mathrm{ZnFe}_{2} \mathrm{O}_{4}$ contents of the EAFDs, as the independent factors (Table 2). The F-value of the $\mathrm{Fe} / \mathrm{Zn}$ ratio with respect to the $\mathrm{Zn}$ extraction rate was 12.26 at the 99\% confidence level $(p<0.005)$. By contrast, for $\mathrm{d}_{50}$, the F-value was as low as 2.42 with high p-values (0.148). High F-values and low p-values $(p<0.05)$ indicate statistically significant variation. Thus, $\mathrm{Zn}$ extraction under the tested conditions was highly affected by the Fe/Zn ratio of the EAFD but not by the particle size. The average $\mathrm{Zn}$ extraction rates were $81.7 \% \pm 5.3 \%$ (95\% confidence interval; 70.0-93.3\%) at $\mathrm{Fe} / \mathrm{Zn}$ ratios $<1,59.8 \%$ $\pm 4.6 \%$ (95\% confidence interval; 49.6-69.7\%) at Fe/Zn ratios of $1-3$, and $35.8 \% \pm 8.0 \%$ (95\% confidence interval; $18.2-53.3 \%$ ) at $\mathrm{Fe} / \mathrm{Zn}$ ratios $>3$. The high correlation between the $\mathrm{Fe} / \mathrm{Zn}$ ratio and the maximum $\mathrm{Zn}$ extraction rate could be affected by different crystal formation mechanisms depending on the $\mathrm{Fe} / \mathrm{Zn}$ ratio. Suetens et al. [12] suggested two $\mathrm{ZnFe}_{2} \mathrm{O}_{4}$ formation mechanisms: a solid-solid reaction and a gas-solid reaction. The relatively large amount of $\mathrm{Zn}$ in EAFD with a low Fe/Zn ratio increases the possibility that $\mathrm{ZnO}$ crystals are generated and precipitated on the surface of the Fe oxide. Through a solid-solid reaction between the two oxides, EAFD with a low $\mathrm{Fe} / \mathrm{Zn}$ ratio is expected to form large spherical crystals covered by fine $\mathrm{ZnO}$ particles, with $\mathrm{ZnFe}_{2} \mathrm{O}_{4}$ formed on the outer surfaces of the spherical Fe oxide crystals 

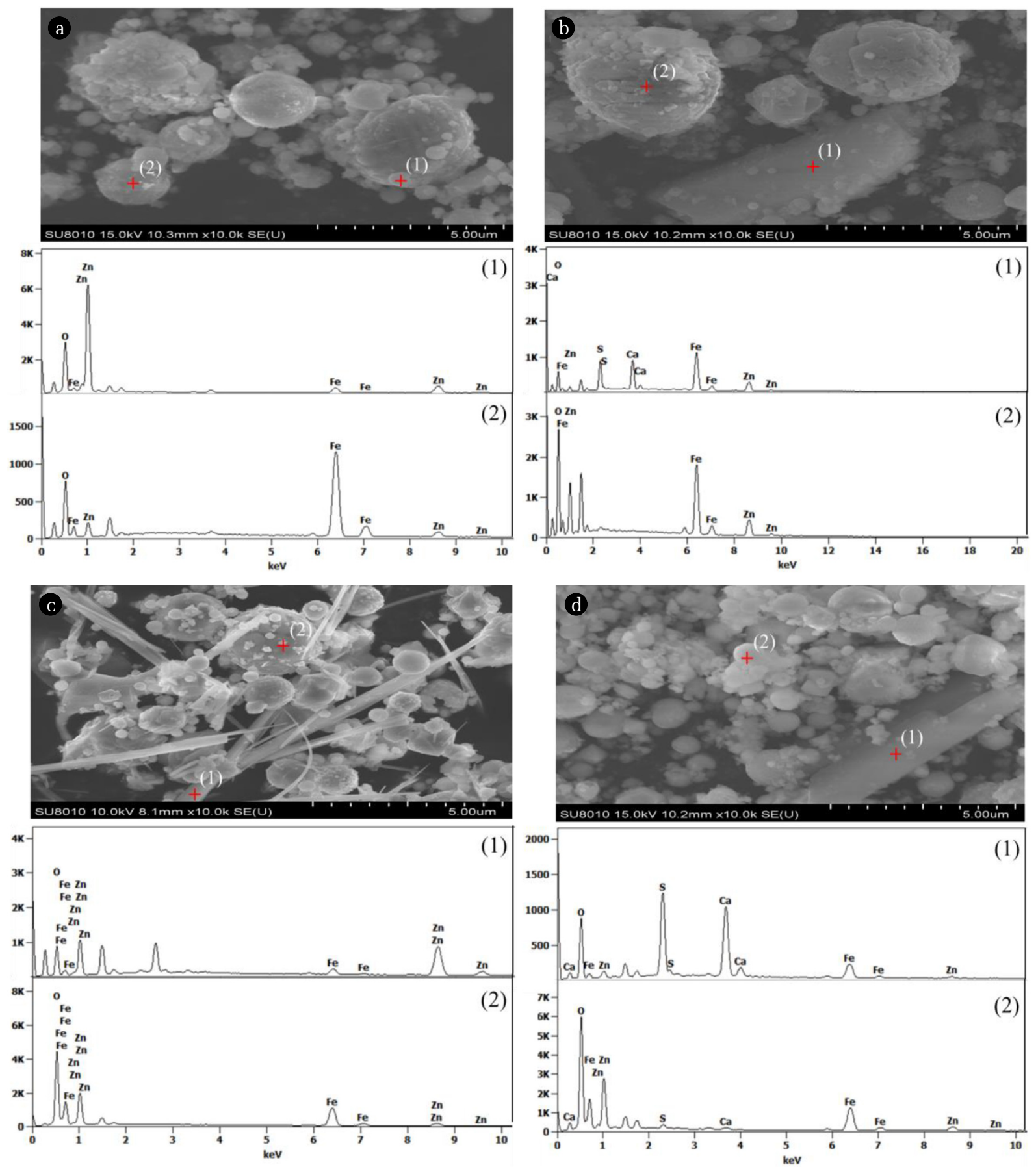

Fig. 3. SEM images and EDS spectra of (a) EAFD 1 , (b) leached residue of $\mathrm{EAFD}_{1}$, (c) $\mathrm{EAFD}_{3}$, and (d) leached residue of EAFD

(Fig. 3(a)). As confirmed by SEM-EDS mapping (Fig. 4), Zn exists on the outer surface of the spherical particles. In contrast, the relatively high Fe content of EAFD with a high Fe/Zn ratio allows Zn vapor to react directly through a gas-solid chemical diffusion reaction to form the spinel phase. By this mechanism, Zn was observed homogeneously throughout the entire crystal (Fig. 4). Consequently, EAFD with a low $\mathrm{Fe} / \mathrm{Zn}$ ratio could have a large amount of $\mathrm{ZnO}$ crystals that dissolve more easily than $\mathrm{ZnFe}_{2} \mathrm{O}_{4}$ during acid leaching, and $\mathrm{ZnFe}_{2} \mathrm{O}_{4}$ can easily be exposed to the acid, resulting in a high $\mathrm{Zn}$ extraction rate. By contrast, the lack of a statistically significant relationship between $\mathrm{Zn}$ extraction and $\mathrm{d}_{50}$ can be explained by EAFD particle aggregation, induced by exposure to air moisture, which can distort the actual particle sizes such as in $\mathrm{EAFD}_{3}$ [10]. 

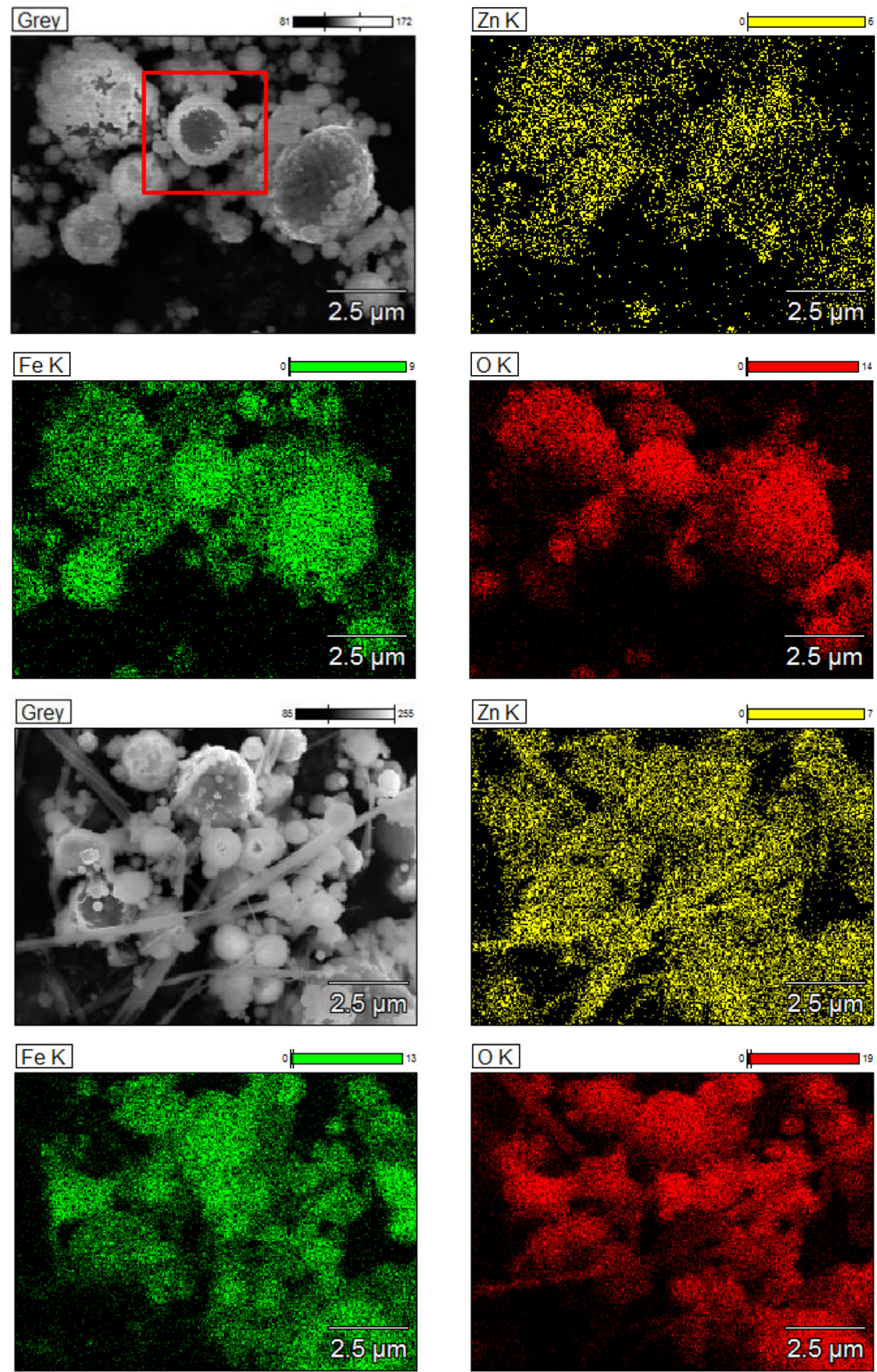

Fig. 4. SEM-EDS mapping results for $\mathrm{EAFD}_{1}$ (up) and $\mathrm{EAFD}_{3}$ (down).

The ANOVA results showed that a high $\mathrm{Fe} / \mathrm{Zn}$ ratio was significantly correlated with a high $\mathrm{ZnFe}_{2} \mathrm{O}_{4}$ content in EAFDs and a low $\mathrm{Zn}$ extraction rate. That is, the lower the $\mathrm{Fe} / \mathrm{Zn}$ ratio in the EAFD, the lower the $\mathrm{ZnFe}_{2} \mathrm{O}_{4}$ content in the sample and the higher the $\mathrm{Zn}$ extraction rate that can be obtained. Thus, it might be possible to use the $\mathrm{Fe} / \mathrm{Zn}$ ratio as a screening factor to select EAFDs for high Zn recovery via acid leaching under ambient conditions. 
Table 2. Summary of ANOVA Results to Evaluate the Influence of Fe/Zn Ratio and Specific Particle Size (d50) on Zn Recovery from EAFDs Using Acid Leaching under Ambient Conditions $\left(20^{\circ} \mathrm{C}, 1 \mathrm{~atm}\right)$

\begin{tabular}{lccccc}
\hline Source & Sum of squares & Degrees of freedom & Mean square & F & Sig. \\
\hline Fe/Zn ratio & $4,144.667$ & 2 & $2,072.333$ & 12.263 & 0.002 \\
Specific particle size $\left(\mathrm{d}_{50}\right)$ & 408.375 & 1 & 408.375 & 2.417 & 0.148 \\
Fe/Zn ratio specific particle size $\left(\mathrm{d}_{50}\right)$ & 26.000 & 2 & 13.000 & 0.077 & 0.926 \\
\hline
\end{tabular}

\subsection{Effect of Acid Leaching Time and L/S Ratio on $\mathrm{pH}$ and Metal Leaching}

During leaching, the acid is consumed by reaction with the metal oxides in the EAFD, resulting in a change in the $\mathrm{pH}$. Thus, the changes in $\mathrm{pH}$ and the dissolution behaviors of $\mathrm{Zn}$ and $\mathrm{Fe}$ from the EAFDs were investigated as a function of leaching time and $\mathrm{L} / \mathrm{S}$ ratio (mL/g). Fig. 5(a) shows the changes in the extraction of $\mathrm{Zn}$ and $\mathrm{Fe}$ from $\mathrm{EAFD}_{1}$ subjected to acid leaching in $1.4 \mathrm{~mol} / \mathrm{L}$ $\mathrm{H}_{2} \mathrm{SO}_{4}$ at $20^{\circ} \mathrm{C}$ and an $\mathrm{L} / \mathrm{S}$ ratio of 3 for $1 \mathrm{~h}$. Zn leaching proceeded very quickly compared with Fe leaching, with $\sim 80 \%$ of the total $\mathrm{Zn}$ content leached within $5 \mathrm{~min}$. This result was attributed to the high acid solubility of $\mathrm{ZnO}$, which is present in the form of fine particles. By contrast, the low initial leaching rate of $\mathrm{Fe}$ $(\sim 5 \%)$ decreased further to $<0.5 \%$ after $30 \mathrm{~min}$. These results could be explained by the Gibbs free energy $\left(\Delta \mathrm{G}^{\circ}, 20^{\circ} \mathrm{C}, 1 \mathrm{~atm}\right)$ of the main oxide components, as given in Eq. (1)-(4) [9]. That is, the more rapid consumption of added acid by $\mathrm{ZnO}$ than by Fe oxides in the EAFD stems from the high negative $\Delta \mathrm{G}^{\circ}$ value for the $\mathrm{ZnO}$ reaction, whereas $\mathrm{Fe}$ oxides and $\mathrm{ZnFe}_{2} \mathrm{O}_{4}$ have relatively low acid solubilities. The $\mathrm{pH}$ of the leaching solution increased sharply from 2 to 4.5 over the initial $30 \mathrm{~min}$ through consumption of the acid or its reaction with a metal oxide (e.g., $\mathrm{ZnO}$ ). As the leaching time elapsed, the leached Fe was converted into Fe(III) hydroxide $\left(\mathrm{Fe}(\mathrm{OH})_{3}\right)$ owing to the increased solution $\mathrm{pH}(>4.5)$ induced by the acid dissolution of metal oxides (i.e., basic anhydrate) [6]. Trivalent $\mathrm{Fe}\left(\mathrm{Fe}^{3+}\right)$ is produced from $\mathrm{ZnFe}_{2} \mathrm{O}_{4}$ by acid leaching (Eq. (4)), and we confirmed that it mostly precipitates as $\mathrm{Fe}(\mathrm{OH})_{3}$ at $\mathrm{pH}>4.5$ using Visual MINTEQ 3.1. Similar results were observed for the EAFDs examined in this study (data not shown), suggesting that leaching of $\mathrm{Zn}$ with minimum Fe dis- solution is possible when the $\mathrm{pH}$ is maintained above 4.5 by adjusting the leaching time [7].

Zn and Fe exhibited similar changes in leaching behavior as a function of $\mathrm{pH}$ (Fig. 5(b)) when the $\mathrm{L} / \mathrm{S}$ ratio $(\mathrm{mL} / \mathrm{g})$ was varied. Specifically, at an L/S ratio of 3 with the solution $\mathrm{pH}$ maintained at 4.5 , selective $\mathrm{Zn}$ extraction ( $>90 \%$ ) with minimum Fe dissolution was achieved. However, when the L/S ratio was increased to $>$ 4, the solution $\mathrm{pH}$ decreased to $<2$, and $8-10 \%$ of $\mathrm{Fe}$ was dissolved.

$$
\begin{aligned}
& \mathrm{ZnO}+\mathrm{H}_{2} \mathrm{SO}_{4}(\mathrm{l}) \rightleftharpoons \\
& \mathrm{ZnSO}_{4}(\mathrm{a})+\mathrm{H}_{2} \mathrm{O}(\mathrm{l}), \triangle \mathrm{G}^{\circ}=-134.57 \mathrm{~kJ} / \mathrm{mol} \\
& \mathrm{Fe}_{2} \mathrm{O}_{3}+3 \mathrm{H}_{2} \mathrm{SO}_{4}(\mathrm{l}) \rightleftharpoons \\
& \mathrm{Fe}_{2}\left(\mathrm{SO}_{4}\right)_{3}(\mathrm{ia})+\mathrm{H}_{2} \mathrm{O}(\mathrm{l}), \triangle \mathrm{G}^{\circ}=-36.24 \mathrm{~kJ} / \mathrm{mol} \\
& \mathrm{Fe}_{3} \mathrm{O}_{4}+4 \mathrm{H}_{2} \mathrm{SO}_{4}(\mathrm{l}) \rightleftharpoons \\
& \mathrm{FeSO}_{4}(\mathrm{ia})+\mathrm{Fe}_{2}\left(\mathrm{SO}_{4}\right)_{3}(\mathrm{ia})+4 \mathrm{H}_{2} \mathrm{O}(\mathrm{l}), \triangle \mathrm{G}^{\circ}=-62.19 \mathrm{~kJ} / \mathrm{mol} \\
& \mathrm{ZnFe}_{2} \mathrm{O}_{4}+4 \mathrm{H}_{2} \mathrm{SO}_{4}(\mathrm{l}) \rightleftharpoons \\
& \mathrm{ZnSO}_{4}(\mathrm{ia})+\mathrm{Fe}_{2}\left(\mathrm{SO}_{4}\right)_{3}(\mathrm{ia})+4 \mathrm{H}_{2} \mathrm{O}(\mathrm{l}), \triangle \mathrm{G}^{\circ}=-67.07 \mathrm{~kJ} / \mathrm{mol}
\end{aligned}
$$

\subsection{Effect of Acid Concentration on $\mathrm{pH}$ and Metal Leaching}

The effect of acid concentration $(0-3 \mathrm{~mol} / \mathrm{L})$ on the leaching efficiencies of $\mathrm{Zn}$ and $\mathrm{Fe}$ was studied under constant conditions (L/S $=3$, leaching time $=30 \mathrm{~min}$, temperature $=20^{\circ} \mathrm{C}$ ) (Fig. 6). To evaluate the effect of leaching time, the results obtained at a leaching time of $5 \mathrm{~min}$ are also presented in Fig. 6. The leaching rate of $\mathrm{Zn}$ increased sharply from $5.8 \%$ to $92 \%$ as the acid concentration
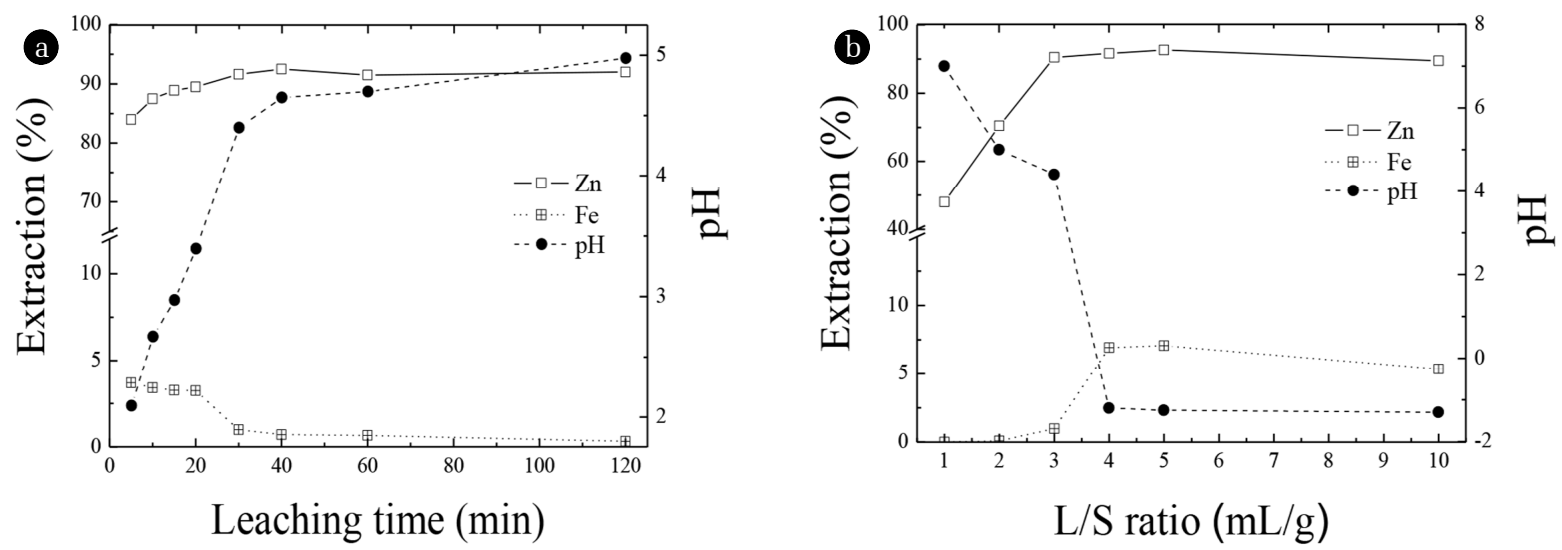

Fig. 5. Changes in metal extraction and $\mathrm{pH}$ as a function of (a) leaching time and (b) $\mathrm{L} / \mathrm{S}$ ratio for EAFD1 in $1.4 \mathrm{~mol} / \mathrm{L} \mathrm{H}_{2} \mathrm{SO} \mathrm{H}_{4}$ at $20^{\circ} \mathrm{C}$. The leaching time for experiment (b) was $30 \mathrm{~min}$. 
increased from 0.1 to $1.4 \mathrm{~mol} / \mathrm{L}$, and reached the maximum leaching rate $(>97 \%)$ at an acid concentration of $2.0 \mathrm{~mol} / \mathrm{L}$. Selective leaching of $\mathrm{Zn}$ without $\mathrm{Fe}$ dissolution was observed at $\mathrm{pH}$ 4.6. Fe was not dissolved until the acid concentration reached $1.4 \mathrm{~mol} / \mathrm{L}$, and the leaching rate was low $(\sim 10 \%)$ even under strongly acidic conditions (3.0 mol/L). This behavior occurs because $\mathrm{ZnO}$ in the EAFD is dissolved easily in the acid solution, whereas the dissolution of Fe components such as Fe oxide and $\mathrm{ZnFe}_{2} \mathrm{O}_{4}$ is quite low (Eq. (1)-(4)). These results were corroborated by the fact that the maximum recoveries $\left(2.0 \mathrm{~mol} / \mathrm{L} \mathrm{H}_{2} \mathrm{SO}_{4}, \mathrm{pH}<\right.$ 0 ) of $\mathrm{Zn}$ and $\mathrm{Fe}$ from $\mathrm{EAFD}_{3,4}$, which contain higher contents of $\mathrm{ZnFe}_{2} \mathrm{O}_{4}$, were lower than those from $\mathrm{EAFD}_{1}$ (Zn: $80 \%$ vs. $98 \%$, Fe: < 5\% vs. 11\%). To verify these results, acid leaching experiments were performed for Fe oxides, $\mathrm{ZnO}$, and $\mathrm{ZnFe}_{2} \mathrm{O}_{4}$ under similar conditions (Table 1, $1.4 \mathrm{~mol} / \mathrm{L} \mathrm{H}_{2} \mathrm{SO}_{4}, \mathrm{~L} / \mathrm{S}=5$, $20^{\circ} \mathrm{C}$ ). $\mathrm{ZnO}$ was extracted very quickly ( $<5 \mathrm{~min}$ ) with a recovery of $>93 \%$, while $\mathrm{ZnFe}_{2} \mathrm{O}_{4}$ showed relatively low extraction ( $\mathrm{Zn}$ : $40 \%$, Fe: $18 \%)$. Notably, hematite $\left(\mathrm{Fe}_{2} \mathrm{O}_{3}\right)$ and magnetite $\left(\mathrm{Fe}_{3} \mathrm{O}_{4}\right)$ showed no acid solubility under the tested leaching conditions (data not shown), suggesting that the leaching of $\mathrm{Fe}$ from the EAFDs occurs mostly via the partial dissolution of the $\mathrm{ZnFe}_{2} \mathrm{O}_{4}$ components.

Examination of the effect of leaching time (Fig. 6) revealed that $\mathrm{Fe}$ in the leachate can be reprecipitated by increasing the $\mathrm{pH}$ from 2.7 to $4.5\left(\right.$ at $\mathrm{H}_{2} \mathrm{SO}_{4}=1.4 \mathrm{~mol} / \mathrm{L}$ ) with an increase in the leaching time from 5 to $30 \mathrm{~min}$. The extraction rate of $\mathrm{Zn}$ also increased from $80 \%$ to $92 \%$ under these conditions. Thus, to obtain a high $\mathrm{Zn}$ recovery rate without Fe leaching, the solution $\mathrm{pH}$ should be maintained at $>4.5$ by adjusting the acid amount and the reaction time, as previously confirmed by the results shown in Fig. 5.

Regardless of the properties of the EAFDs and the acid type used, a $\mathrm{pH}$ of $>4.5$ ensured the highest extraction of $\mathrm{Zn}$ while minimizing Fe leaching. Decreasing the $\mathrm{pH}$ of the leaching solution from $\sim 4.6$ to $<0$ by increasing the acid concentration to $2 \mathrm{~mol} / \mathrm{L}$ $\mathrm{H}_{2} \mathrm{SO}_{4}$ increased the $\mathrm{Zn}$ recovery rates of $\mathrm{EAFD}_{1-4}$ from $\sim 2 \%$ to

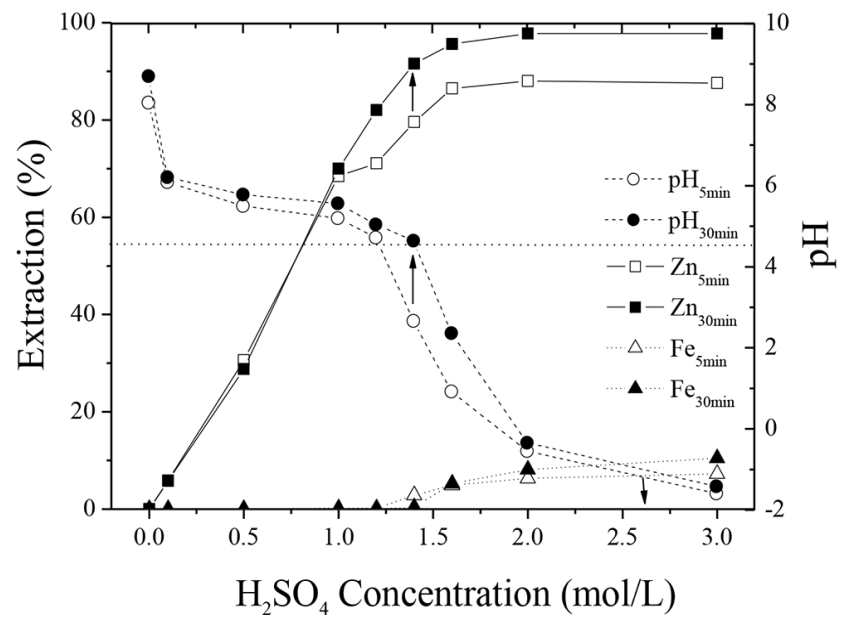

Fig. 6. Changes in metal extraction and $\mathrm{pH}$ with respect to time (5 or $30 \mathrm{~min}$ ) and initial $\mathrm{H}_{2} \mathrm{SO}_{4}$ concentration for EAFD 1 at $20^{\circ} \mathrm{C}$ and an L/S ratio of 3 .
$10 \%$, but the Fe dissolution levels increased from $1.5 \%$ to $8.1 \%$. The leaching behaviors of $\mathrm{Zn}$ and $\mathrm{Fe}$ as a function of $\mathrm{pH}$ were similar when $\mathrm{HCl}$ was used under the same reaction conditions $(\mathrm{L} / \mathrm{S}=3$, reaction time $=30 \mathrm{~min}, 300 \mathrm{rpm})$ [18]. The optimum $\mathrm{HCl}$ concentration for leaching of $\mathrm{Zn}$ with minimum $\mathrm{Fe}$ dissolution was $1.2 \mathrm{~mol} / \mathrm{L}$, corresponding to a solution $\mathrm{pH}$ of 4.9 (data not shown). These results suggest that the $\mathrm{pH}$ of the leaching solution can be used as a process control factor to facilitate the leaching of $\mathrm{Zn}$ without Fe, irrespective of the type of acid used and the properties of the EAFDs [19-21]. In particular, Behnajady and Moghaddam [19], who studied the effects of various parameters (temperature, reaction time, L/S ratio, stirring speed, and $\mathrm{pH}$ ) on the extraction of metals from a $\mathrm{Zn}$ plant hot purification filter cake, reported that the $\mathrm{pH}$ had the strongest effect on the selective leaching of $\mathrm{Zn}$. On the other hand, the concentrations of lead and cadmium in the acid leaching solution of $\mathrm{EAFD}_{1-4}$ were very low (0.3-0.7 mg/L and ND (not detected)-0.3 $\mathrm{mg} / \mathrm{L}$, respectively, as determined by ICP-MS), and the metals remaining in solution could be removed by subsequent Zn refining, which is commonly performed by reductive precipitation using Zn powder [6].

Furthermore, Fig. 1 shows the XRD patterns of the residues of $\mathrm{EAFD}_{2}$ and $\mathrm{EAFD}_{3}$ separated from the leaching solution after reaction at $\mathrm{pH} 4.5$ (reaction time $=30 \mathrm{~min}, \mathrm{~L} / \mathrm{S}=3$, temperature $=20^{\circ} \mathrm{C}$ ). No $\mathrm{ZnO}$ peak was observed in the XRD patterns of the leached residues, whereas the $\mathrm{ZnFe}_{2} \mathrm{O}_{4}$ peak intensity for the leached residues increased relative to that for the EAFDs before acid leaching. An $\mathrm{Fe}(\mathrm{OH})_{3}(\mathrm{~s})$ peak was only observed for the leached residues, but the peak intensity was low owing to the very small amount of Fe dissolved from the EAFD. $\mathrm{CaSO}_{4}(\mathrm{~s})$ and $\mathrm{PbSO}_{4}(\mathrm{~s})$ peaks were also observed, which may be attributed to the reaction of $\mathrm{Ca}$ and $\mathrm{Pb}$ ions in the EAFDs with $\mathrm{H}_{2} \mathrm{SO}_{4}$ (Eq. (5) and (6)). Further, the SEM-EDS results for the leached residues (Fig. 3(c) and 3(d)) indicated that $\mathrm{ZnFe}_{2} \mathrm{O}_{4}$ consisted of spherical particles of various sizes, whereas $\mathrm{CaSO}_{4}$ consisted of needle-like crystals of 5-10 $\mu \mathrm{m}$ in length and 1-2 $\mu \mathrm{m}$ in diameter [22]. The $\mathrm{ZnO}$ crystals disappeared owing to total dissolution during acid leaching. However, $\mathrm{Fe}(\mathrm{OH})_{3}$ and $\mathrm{PbSO}_{4}$ crystals were difficult to identify by SEM-EDS owing to their very low contents in the leached residues.

$\mathrm{CaSO}_{4}(\mathrm{~S}) \rightleftharpoons \mathrm{Ca}^{2+}(\mathrm{aq})+\mathrm{SO}_{4}^{2-}(\mathrm{aq}), \mathrm{K}_{\mathrm{sp}}=2.0 \times 10^{-5}\left(\right.$ at $\left.25^{\circ} \mathrm{C}\right)(5)$
$\mathrm{PbSO}_{4}(\mathrm{~s}) \rightleftharpoons \mathrm{Pb}^{2+}(\mathrm{aq})+\mathrm{SO}_{4}^{2-}(\mathrm{aq}), \mathrm{K}_{\mathrm{sp}}=1.9 \times 10^{-8}\left(\right.$ at $\left.25^{\circ} \mathrm{C}\right)(6)$

\section{Conclusions}

We investigated the main characteristics of EAFDs that yielded a high $\mathrm{Zn}$ recovery rate and a suitable $\mathrm{pH}$ range for selective Zn leaching via the acid leaching process. Comparative analysis of the physicochemical properties of the EAFDs revealed that an $\mathrm{Fe} / \mathrm{Zn}$ ratio of $<1$ indicates a lower content of $\mathrm{ZnFe}_{2} \mathrm{O}_{4}$ than of $\mathrm{ZnO}$ and a smaller particle size distribution. The ANOVA results showed a significant correlation between the Fe/Zn ratio and the $\mathrm{Zn}$ extraction rate $(p<0.005)$; in samples with an $\mathrm{Fe} / \mathrm{Zn}$ ratio $<1$, the mean $\mathrm{Zn}$ extraction rate was $81.7 \% \pm 5.3 \%$. Hence, 
EAFDs with a low Fe/Zn ratio could have a larger amount of $\mathrm{ZnO}$ crystals, which easily dissolve during acid leaching, than $\mathrm{ZnFe}_{2} \mathrm{O}_{4}$; further, the morphological structure of the $\mathrm{ZnFe}_{2} \mathrm{O}_{4}$ in EAFD particles can be easily exposed to the acid, resulting in a high Zn extraction rate under mild leaching conditions. On the other hands, it also confirmed that $\mathrm{Zn}$ can be selectively leached with minimum Fe dissolution by controlling the $\mathrm{pH}$ at $>4.5$ with an appropriate acid amount and time, regardless of the other acid leaching conditions or the properties of the EAFDs. Thus, $\mathrm{pH}$ can be used as a useful operating factor to achieve selective recovery of $\mathrm{Zn}$ from various EAFDs without further $\mathrm{Fe}$ leaching. Considering the fact that EAFDs containing a large amount of acid-insoluble Zn ferrite require harsh leaching condition (e.g., high temperature and pressures) to obtain high $\mathrm{Zn}$ recovery, the pre-selection of EAFDs based on their Fe/Zn ratios and the application of $\mathrm{pH}$ control during acid leaching will assure such a high Zn recovery in a mild leaching condition and/or even under ambient conditions by separating the $\mathrm{Zn}$ ferrites with high Fe content, which can provide a more economical Zn recovery process.

\section{Acknowledgments}

This study was supported by the Research Program funded by Seoul National University of Science and Technology.

\section{References}

1. Wu S, Chang F, Zhang J, Lu H, Kou M. Cold strength and high temperature behaviors of self-reducing briquette containing electric arc furnace dust and anthracite. ISIJ Int. 2017;57:1364-1373.

2. Lanzerstorfer C. Electric arc furnace (EAF) dust: Application of air classification for improved $\mathrm{Zn}$ enrichment in in-plant recycling. J. CLEAN Prod. 2018;174:1-6.

3. Sofilić T, Rastovčan-Mioč A, Cerjan-Stefanović Š, NovoselRadović V, Jenko M. Characterization of steel mill electric-arc furnace dust. J. Hazard. Mater. 2004;109:59-70.

4. Kelebek S, Yörük S, Davis B. Characterization of basic oxygen furnace dust and $\mathrm{Zn}$ removal by acid leaching. Miner. Eng. 2004;17:285-291.

5. de Buzin PJWK, Heck NC, Vilela ACF. EAF dust: An overview on the influences of physical, chemical and mineral features in its recycling and waste incorporation routes. J. Mater. Res. Technol. 2017;6:194-202.

6. Kukurugya F, Vindt T, Havlík T. Behavior of Zn, Fe and calcium from electric arc furnace (EAF) dust in hydrometallurgical processing in sulfuric acid solutions: Thermodynamic and kinetic aspects. Hydrometallurgy 2015;154:20-32.

7. Langová Š, Matýsek D. Zn recovery from steel-making wastes by acid pressure leaching and hematite precipitation. Hydrometallurgy 2010;101:171-173.

8. Montenegro V, Oustadakis P, Tsakiridis PE, Agatzini-Leonardou S. Hydrometallurgical treatment of steelmaking electric arc furnace dusts (EAFD). Metall. Mater. Trans. B 2013;44:1058-1069.
9. Havlik T, Turzakova M, Stopic S, Friedrich B. Atmospheric leaching of EAF dust with diluted sulphuric acid. Hydrometallurgy 2005;77:41-50.

10. Mantovani MC, Takano C, Büchler PM. EAF and secondary dust characterisation. Femak. Steelmak. 2004;31:325-332.

11. Havlik T, Maruskinova G, Miskufova A. Determination of ZnO amount in electric arc furnace dust and temperature dependence of leaching in ammonium carbonate by using of X-ray diffraction. Arch. Metall. Mater. 2018;63:653-658.

12. Suetens T, Guo M, Van Acker K, Blanpain, B. Formation of the $\mathrm{ZnFe}_{2} \mathrm{O}_{4}$ phase in an electric arc furnace off-gas treatment system. J. Hazard. Mater. 2015;287:180-187.

13. Tsakiridis PE, Oustadakis P, Katsiapi A, Agatzini-Leonardou S. Hydrometallurgical process for Zn recovery from electric arc furnace dust (EAFD). Part II: Downstream processing and Zn recovery by electrowinning. J. Hazard. Mater. 2010;179:8-14.

14. Zhang D, Zhang X, Yang T, et al. Selective leaching of Zn from blast furnace dust with mono-ligand and mixed-ligand complex leaching systems. Hydrometallurgy 2017;169:219-228.

15. Machado JGMS, Brehm FA, Moraes CAM, dos Santos CA, Vilela ACF, da Cunha JBM. Chemical, physical, structural and morphological characterization of the electric arc furnace dust. J. Hazard. Mater. 2006;B136:953-960.

16. Oustadakis P, Tsakiridis PE, Katsiapi A, Agatzini-Leonardou S. Hydrometallurgical process for Zn recovery from electric arc furnace dust (EAFD). Part I: Characterization and leaching by diluted sulphuric acid. J. Hazard. Mater. 2010;179:1-7.

17. Sekula R, Wnek M, Selinger A, Wrobel M. Electric arc furnace dust treatment: investigation on mechanical and magnetic separation methods. Waste Manage. Res. 2001;19:271-275.

18. Langová Š, Leško J, Matýsek D. Selective leaching of Zn from Zn ferrite with hydrochloric acid. Hydrometallurgy 2009;95: 179-182.

19. Behnajady B, Moghaddam J. Selective leaching of Zn from hazardous as-bearing $\mathrm{Zn}$ plant purification filter cake. Chem. Eng. Res. Des. 2017;117:564-574.

20. Montenegro V, Agatzini-Leonardou S, Oustadakis P, Tsakiridis PE. Hydrometallurgical treatment of EAF dust by direct sulphuric acid leaching at atmospheric pressure. Waste Biomass Valori. 2016;7:1531-1548.

21. Aygun A, Dogan S, Argun ME, Ates H. Removal of sulphate from landfill leachate by crystallization. Environ. Eng. Res. 2019;24:24-30.

22. Li Y, Lu C, Zhang H, Li J. Experimental study on chemical activation of recycled powder as a cementitious material in mine paste backfilling. Environ. Eng. Res. 2015;21:341-349.

23. Havlík T, e Souza BV, Bernardes AM, Schneider IAH, Miškufová A. Hydrometallurgical processing of carbon steel EAF dust. J. Hazard. Mater. 2006;135:311-318.

24. Antuñano N, Cambra JF, Arias PL. Development of a combined solid and liquid wastes treatment integrated into a high purity $\mathrm{ZnO}$ hydrometallurgical production process from Waelz oxide. Hydrometallurgy 2017;173:250-257.

25. Shawabkeh RA. Hydrometallurgical extraction of $\mathrm{Zn}$ from Jordanian electric arc furnace dust. Hydrometallurgy 2010;104: 61-65.

26. Kul M, Oskay KO, Şimşir M, Sübütay $H$, Kirgezen $H$. Optimization of selective leaching of $\mathrm{Zn}$ from electric arc fur- 
nace steelmaking dust using response surface methodology. Trans. Nonferrous Met. Soc. China 2015;25:2753-2762.

27. Han H, Sun W, Hu Y, Tang H, Yue T. Magnetic separation of Fe precipitate from nickel sulfate solution by magnetic seeding. Hydrometallurgy 2015:156:182-187. 